\title{
On the Reversion of an Alanyl-tRNA Synthetase Mutant of Mammalian Cells
}

\author{
Koki Sato \\ Division of Genetics, National Institute of Radiological Sciences, 4-9-1 Anagawa, \\ Chiba 280, Japan
}

\begin{abstract}
Several spontaneous revertants able to grow in restrictive temperature $\left(39^{\circ}\right)$ were isolated from a temperature-sensitive mutant (ts3) of murine leukemic cells L5178Y. The revertants showed reduced plating efficiencies and prolonged doubling times at $39^{\circ} \mathrm{C}$ when compared with wild type cells. The alanyl-tRNA synthetase activity was thermolabile in both ts 3 cells and the revertants, indicating suppression as the mechanism of reversion. It was also demonstrated that glycerol protected the enzyme from thermal inactivation. The specific activities of alanyl-tRNA synthetase and alanine aminotransferase did not differ much in the wild type, mutant, and revertant cells. This indicates the unlikelihood of thermolabile enzyme overproduction or of increased intracellular concentration of $\mathrm{L}$-alanine causing phenotypic suppression in these revertants. The mechanism of suppression is discussed.
\end{abstract}

A number of unsolved problems exist in mutation studies of mammalian cells, such as genetic versus epigenetic mechanisms for unstable phenotypes, ploidy effects on mutation induction, and requirements for prolonged expression time. These problems can be approached by either forward or reverse mutations of biochemically defined markers. Only a few markers, however, are available, and this report demonstrates a new marker, an alanyl-tRNA synthetase mutation, which may be useful for elucidating the mechanisms of reversion. It is known that reverse mutations are either true reversions or suppressions. True reversions restore the original nucleotide sequence in DNA, whereas suppressions result from second site mutations. In bacterial systems, intragenic, informational, and indirect suppressions have been described (4). Intragenic suppressions arise from either base change or frameshift within the same cistron. Informational suppressions concern alterations of ribosome or tRNA. Indirect suppressions result from the second mutation which either opens an alternate pathway of deficient metabolic synthesis, or substitutes the defective function by a second enzyme, or provides cytoplasmic conditions which stabilize the unstable mutant enzyme. The question is asked whether these mechanisms of suppression are also operative in mammalian cells.

\section{MATERIALS AND METHODS}

Cells. A temperature-sensitive mutant ts 3 of murine leukemic cells L5178Y was used. This mutant has been described previously (8) and characterized as possessing a thermolabile alanyl-tRNA synthetase (7). The original L5178Y cells are designated as the wild type. All cells 
were grown in Fischer's medium supplemented with $10 \%$ calf serum.

Preparation of cell extracts. Cells grown in spinner cultures were harvested by centrifugation, washed with phosphate-buffered saline, and homogenized with a motor-driven Teflon homogenizer. The cell homogenate was centrifuged at $27,000 \times \mathrm{g}$ for $15 \mathrm{~min}$ and the supernatant fraction was adjusted to $\mathrm{pH}$ 5.2. The precipitate was collected and used for alanyl-tRNA synthetase asaay. The $27,000 \times \mathrm{g}$ supernatant fraction was used for alanine aminotransferase assay. Protein was determined by the method of Lowry et al. (5).

Alanyl-tRNA synthetase assay. A reaction mixture of $0.1 \mathrm{ml}$ contained $100 \mathrm{mM}$ Tris-HCI (pH7.5), $10 \mathrm{mM} \mathrm{KCI}, 4 \mathrm{mM}$ magnesium acetate, $5 \mathrm{mM}$ ATP, $2 \mathrm{mM}$ dithiothreitol, $10 \mu \mathrm{g}$ rat liver tRNA, $15 \mu \mathrm{M}{ }^{14} \mathrm{C}$-alanine $(159 \mathrm{Ci} / \mathrm{mol})$, and pH5.2 fraction. After incubation at $30^{\circ} \mathrm{C}$ for $15 \mathrm{~min}$, the reaction was terminated by the addition of ice-cold $10 \%$ trichloroacetic acid. The mixture was left for $30 \mathrm{~min}$ in ice, and the precipitates were collected on presoaked Whatman GF/F glass fiber filters, washed three times with ice-cold $5 \%$ trichloroacetic acid, and washed twice with $95 \%$ ethanol. The filters were dried and counted in a liquid scintillation counter.

Alanine aminotransferase assay. The procedure was essentially the same as described by Reitman and Frankel (6). A reaction mixture of $0.5 \mathrm{ml}$ containing $1 \mu \mathrm{M} \alpha$-ketoglutarate, 100 $\mu \mathrm{M}$ DL-alanine, and $100 \mathrm{mM}$ phosphate buffer (pH7.4) was mixed with $0.1 \mathrm{ml}$ of cell extract. After incubation at $30^{\circ} \mathrm{C}$ for $30 \mathrm{~min}, 0.5 \mathrm{ml}$ of 2, 4-dinitro-phenylhydrazine $(1 \mathrm{mM})$ was added to stop the reaction. The mixture was left at room temperature for $20 \mathrm{~min}$, followed by the addition of $5 \mathrm{ml}$ of $0.4 \mathrm{~N}$ sodium hydroxide. At the end of $30 \mathrm{~min}$, the optical density of the solution was measured at $505 \mathrm{~nm}$ using water as the blank. The observed absorbances were calibrated with authentic lithium pyruvate solution.

\section{RESULTS}

Isolation of revertants from ts 3 cells. Temperature-sensitive mutant ts 3 cells normally grow at $33^{\circ} \mathrm{C}$ but not at $39^{\circ} \mathrm{C}$ on agar plates. Rare revertants showed growth at $39^{\circ} \mathrm{C}$. The spontaneous reversion frequency of ts 3 mutation was 14 per million cells (Table 1).

TABLE 1. Plating efficiencies of Wild type, mutant, AND Revertant

\begin{tabular}{lccl}
\multicolumn{4}{c}{ CELLS AT $39^{\circ}$ AND $33^{\circ} \mathrm{C}$} \\
\hline Cell & \multicolumn{2}{c}{ Plating efficiency $(\%)$} & Ratio \\
& $39^{\circ} \mathrm{C}$ & $33^{\circ} \mathrm{C}$ & $39^{\circ} / 33^{\circ}$ \\
\hline L5178Y & 48 & 87 & 0.55 \\
ts3 & 0.00063 & 43 & 0.000014 \\
R303 & 10 & 43 & 0.23 \\
R313 & 4 & 38 & 0.11 \\
RN09 & 1 & 17 & 0.06 \\
\hline
\end{tabular}

Colonies which developed at $39^{\circ} \mathrm{C}$ were collected and designated in series from R1. Their growth characteristics were examined. As shown in Table 1, the plating efficiencies were considerably lower in the revertants than in the wild type cells at $39^{\circ} \mathrm{C}$. These lower plating efficiencies in the revertants indicate that reversion to the wild type was unlikely.

The population doubling times of revertants were determined to examine whether reverse mutation exerted any effect on cell growth. Table 2 shows that ts 3 cells grew slower than wild type cells at $33^{\circ} \mathrm{C}$. Revertants had almost the same growth rates as 
ts 3 cells at $33^{\circ} \mathrm{C}$, but have far longer doubling times than wild type cells at $39^{\circ} \mathrm{C}$. Furthermore, Table 2 shows that cell growth was accelerated at higher temperature in wild type cells but not in revertants. These results indicate that revertant cells inherited the slow growth rate from parental ts 3 cells but acquired the ability to grow at $39^{\circ} \mathrm{C}$.

TABLE 2. GROWTH RATES OF WILD TYPE, MUTANT, AND REVERTANT CELLS AT $33^{\circ}$ AND $39^{\circ} \mathrm{C}$

\begin{tabular}{lcc}
\hline & \multicolumn{2}{c}{ Doubling time (hours) } \\
\cline { 2 - 3 } & $33^{\circ} \mathrm{C}$ & $39^{\circ} \mathrm{C}$ \\
\hline L5178Y & 15.3 & 13.3 \\
ts3 & 20.3 & Infinite \\
R303 & 19.7 & 21.0 \\
R308 & Not determined & 21.7 \\
R313 & 22.1 & 23.7 \\
RN07 & Not determined & 29.7 \\
RN08 & Not determined & 22.0 \\
RN09 & 20.7 & 21.4 \\
\hline
\end{tabular}

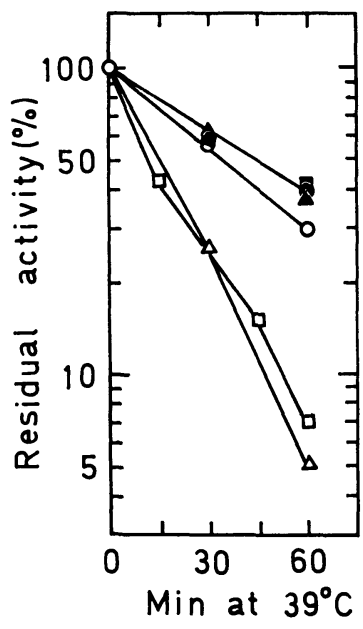

Fig. 1. Thermal inactivation of alanyl-tRNA synthetase activities of wild type $(\bigcirc, \bigcirc)$, ts3 $(\triangle, \Delta)$, and revertant R303 ( $\square, \square)$. The pH5.2 fractions were incubated at $39^{\circ} \mathrm{C}$ for various time periods, and the residual activities were determined. Solid symbols indicate the addition of glycerol to pH5.2 fractions (final concentration, $50 \%$ ).
Thermal stability of alanyl-tRNA synthetase activities. In the previous report (7) I showed that the alanyltRNA synthetase activity was far more thermolabile in ts 3 cells than in wild type cells. If the revertants result from true reversion, the synthetase activity of the revertants should be as stable as that of the wild type cells. Hence, enzyme preparations from revertants were examined for thermal stability. As shown in Fig. 1, the thermal inactivation curve of alanyl-tRNA synthetase activity of revertant R303 did not differ much from that of ts 3 cells, both being unstable compared to the wild type cells. However, glycerol added to enzyme preparations to a final concentration of 50 percent protected these unstable enzyme activities from heat inactivation (Fig. 1). Other revertants were also investigated for enzyme stability. Table 3 shows that the synthetase activities of all revertants examined were as unstable as the synthetase activity of ts 3 cells, and never reached the level of the wild type enzyme. These results indicate that the revertants did not arise from reversals of the original mutational site, but from some sort of suppression.

Specific activities of alanyl-tRNA synthetase in pH5.2 fractions. Since the revertants still possess a thermolabile enzyme, one possible mechanism of reversion is the increase in the specific activity or overproduction of unstable enzyme. Such possibilities were tested by measuring the specific activity of alanyl-tRNA synthetase in the pH5.2 fractions prepared from revertant, 
TABLE 3. THERMAL STABILITY OF ALANYL-tRNA SYNTHETASE ACTIVITY OF REVERTANTS

\begin{tabular}{lc}
\hline Cell & Residual activity $(\%)$ \\
\hline R2 & $a$ \\
R102 & 3.4 \\
R103 & 3.5 \\
R104 & 3.4 \\
R105 & 1.3 \\
R106 & 4.7 \\
R114 & 4.3 \\
R207 & 2.0 \\
RN09 & 3.0 \\
\hline
\end{tabular}

$a$ Ratio of the residual activity after 60 min-incubation at $39^{\circ} \mathrm{C}$ to the activity at time zero.

TABLE 4. SPECIfIC ACtIVITIES OF ALANYL-tRNA SYNTHETASE IN pH5.2 FRACTIONS

\begin{tabular}{lc}
\hline Cell & $\begin{array}{c}\text { Specific activity } \\
\text { (p mol alanyl-tRNA/min/mg protein) }\end{array}$ \\
\hline L5178Y & 0.54 \\
ts3 & 0.57 \\
R2 & 0.59 \\
R4 & 0.50 \\
R103 & 0.54 \\
R116 & 0.26 \\
R207 & 0.50 \\
R303 & 0.52 \\
RN09 & 0.14 \\
\hline
\end{tabular}

TABLE 5. SPECIFIC ACTIVITIES OF ALANINE AMINOTRANSFERASE IN CELL EXTRACTS

\begin{tabular}{lc}
\hline Cell & $\begin{array}{c}\text { Specific activity } \\
\text { (n mol pyruvate/min/mg protein) }\end{array}$ \\
\hline L5178Y & 2.1 \\
ts3 & 1.9 \\
R1 & 2.0 \\
R207 & 3.2 \\
R303 & 2.3 \\
R313 & 3.0 \\
RN09 & 3.6 \\
\hline
\end{tabular}

mutant, and wild type cells. As shown in Table 4, the specific activities of revertants were either roughly equal to or lower than those of the mutant or wild type cells. Thus, it is unlikely that revertants acquired increased "specific "activity" or overproduced synthetase.

Specific activities of alanine aminotransferase in cell extracts. An alternative mechanism of reversion should be considered that is independent of qualitative or quantitative changes of alanyl-tRNA synthetase activity. As demonstrated in the previous report (7), the mutant phenotype of ts 3 cells is suppressed by adding excess alanine to growth medium. Therefore, it is possible that the intracellular level of alanine may be increased in the revertants. Since a direct assay of alanine concentration is not feasible here, we approached the problem in a different way. We measured the specific activity of alanine aminotransferase which is the key enzyme in the main pathway of L-alanine 
biosynthesis. Table 5 shows that the specific activities of revertants are one to two times as high as those of wild type and mutant cells. It seems rather unlikely, however, that the reversion is accounted for by the two-fold increase in the specific activity of alanine aminotransferase, since the maximal level of phenotypic suppression requires 10 millimolal L-alanine, that is 100 times as high as the concentration contained in Ham's F12 medium (7).

\section{DISCUSSION}

The present report showed that revertants of an alanyl-tRNA synthetase mutant in a mammalian cell line still possessed the enzyme of the mutant type rather than the wild type. This indicates that the reversion resulted from suppression.

In Chinese hamster cells, a revertant of a leucyl-tRNA synthetase mutant had a synthetase which was qualitatively and quantitatively different from the enzyme of either the mutant or wild type cells (2).

In bacteria, reversion has been studied extensively in several aminoacyl-tRNA synthetase mutants. In the case of a glycyl-tRNA synthetase mutant $(3,9$,$) , revertants$ were divided into four classes: (a) tandem duplications of the synthetase gene, (b) glycine dissimilation mutants, (c) closely linked suppressors, and (d) other suppressors or stable duplications. It has been shown that class (a) is the most frequent type and that this type of reversion is genetically unstable. This point was examined in the present report, and the preliminary experiment showed that ts 3 revertants were stable.

In the case of alanyl-tRNA synthetase mutant of bacteria, revertants possessed altered ribosomal proteins $(1,10)$. The biochemical studies demonstrated that the mechanism of suppression by ribosomal mutations was not due to increased translational ambiguity but due to the reduced rate of polypeptide synthesis, thus rendering the revertant cells compatible with the slow supply of alanyl-tRNA by a thermolabile enzyme. The reduced rate of polypeptide synthesis leads to reduced cell growth. A similar mechanism could be operative in ts 3 revertants, since the doubling times were far longer in revertants than in wild type cells. However before coming to this conclusion, it is necessary to demonstrate alterations of ribosomal proteins in ts 3 revertants and to determine the intracellular level of $\mathrm{L}$-alanine. It is also conceivable that revertants have some kind of protective mechanism, such as glycerol.

Acknowledgment. The author wishes to express his thanks to Miss Naoko Hieda for excellent technical assistance. This work was supported in part by grants from the Ministry of Education, Science and Culture.

\section{REFERENCES}

1. Buckel, F., W. Piepersberg, and A. Böck. Suppression of temperature-sensitive aminoacyltRNA synthetase mutations by ribosomal mutations: A possible mechanism. Mol. Gen. Genet. 149, 51-61, 1976

2. Farber, R.A., and M.P. Deutscher. Physiological and biochemical properties of a temperature-sensitive leucyl-tRNA synthetase mutant (tsH1) and revertant from Chinese hamster cells. Somat. Cell Genet. 2, 509-520, 1976

3. FoLK, W.R., and P. BERG. Duplication of the structural gene for glycyl-transfer RNA synthetase in Escherichia coli. J. Mol. Biol. 58, 595-610, 1971

4. Gorini, L., and J.R. Beckwith. Suppression. Ann. Rev. Microbiol. 20, 401-422, 1966 
5. Lowry, O.H., N.J. Rosebrough, A.L. Farr and R.J. Randall. Protein measurement with the Folin phenol reagent. J. Biol. Chem. 193, 265-275, 1951

6. Reitman, S., and S. Frankel. A colorimetric method for the determination of serum glutamic oxalacetic and glutamic pyruvic transaminases. Am. J. Clin. Pathol. 28, 56-63, 1957

7. SATo, K. A leukaemic cell mutant with a thermolabile alanyl-transfer RNA synthetase. Nature 257, 813-815, 1975

8. Sato, K., and T. Shiomi. Isolation of temperature-sensitive mutants from murine leukemic cells (L5178Y). Exp. Cell Res. 88, 295-302, 1974

9. Straus, D.S. Induction by mutagens of tandem gene duplications in the glyS region of the Escherichia coli chromosome. Genetics 78, 823-830, 1974

10. Wittmann, H.G., G. Stöffler, W. Piepersberg, P. Buckel, D. Ruffler and A. Böck. Altered S5 and S20 ribosomal proteins in revertants of an alanyl-tRNA synthetase mutant of Escherichia coli. Mol. Gen. Genet. 134, 225-236, 1974

(Received for publication, August 19, 1977) 